\title{
LA “TRANSPARENCIA" EN LA HAGIOGRAFÍA DE SOR SEBASTIANA
}

\author{
Katarína Korbová \\ Universidad Carolina de Praga
}

\begin{abstract}
Resumen
El trabajo presente trata el problema de la "transparencia" del lenguaje ascético-místico en la "vida" de sor Sebastiana de la SS. Trinidad, una importante religiosa novohispana, cuya vida fue marcada por los encuentros sobrenaturales con Dios. El discurso tiene que ver con la cuestión de la corporalidad del discurso barroco. El texto desentraña diferentes recursos estilísticos y temáticos, comparándolos con las imágenes de santa Teresa de Jesús. Se centra ante todo en los símbolos que tienen que ver con el campo semántico de la luz.
\end{abstract}

Palabras clave: Mística, hagiografía, símbolos, visiones.

\begin{abstract}
The present article analyses the problem of "transparency" of the mystical language in "vida" of sor Sebastiana, who was a well-known nun in colonial Mexico. Her life was influences by his supernatural encounters with God. The text presents the themes of a baroque discourse, for example, it is marked by the corporality of her visions. The article tries to study different stylistic figures and relates them to the symbols of saint Teresa of Avila.
\end{abstract}

Keywords: Mysticism hagiography simbols visions

\section{Introducción}

Espinosa (167) hace una diferenciación entre la mística europea y la americana (examina ante todo la zona andina). Dice que el misticismo es "el esfuerzo imposible de comunicar la tenue e incompleta comunicación que el hombre o la mujer lleva a cabo con un Dios ausente y opaco". A eso se opone el barroco colonial. Las místicas y visionarias americanas no tienen dificultad en entablar la comunicación con su Esposo. Tampoco tienen dificultad en expresar, de una manera elocuente, sus vivencias. La 
experiencia se lleva a cabo a través de los sentidos, del cuerpo, del dolor, del sufrimiento, del gozo y del placer. Allí es donde nace la analogía de la "oscuridad" y "transparencia" en las vivencias respectivas.

Quisiera partir de esa hipótesis. Mi propósito es analizar el lenguaje figurativo en la Vida de ven. Sor Sebastiana Josepha de la SS. Trinidad. Me centraré ante todo en las imágenes que tienen que ver con la luz. Mi intención es estudiar hasta qué punto podemos decir que el lenguaje místico, que aparece en la obra apunta más hacia la "transparencia" de las vivencias trascendentales, mientras que la mística española se caracteriza por cierta "opacidad". Para ello, será importante tanto exponer primero el origen del texto hagiográfico, que contiene la vida interior de la religiosa. En segundo lugar, estudiaré algunos temas relacionados con la mística y los recursos figurativos principales.

\section{La "vida" de sor Sebastiana}

Sebastiana Josefa de la Trinidad Maya Samaniego nace el 19 de enero de 1709 y muere en 1757. Fue monja clarisa en el monasterio de la Ciudad de México. La religiosa destacó ante todo por su actividad visionaria. Además de tener una existencia virtuosa, según los modelos cristianos de santidad, fue venerada por sus coetáneos y su existencia fue trazada por José
Eugenio Valdés, uno de sus confesores. El conocimiento que tenemos hoy de su vida es gracias a su obra autobiográfica, por un lado, y también debido al texto bio-hagiográfico de José Eugenio Valdés. Una vez profesa en el convento de San Juan de la Penitencia, uno de sus confesores, el franciscano Lozano, le pide que escriba sus vivencias exteriores e interiores (Valdés 1765, 422). La escritura conventual no fue algo atípico en el mundo novohispano. Por ejemplo, Asunción Lavrin y Josefina Murial identificaron 121 textos hagiogáficos, usando como base la escritura de monjas (Ibsen 1998).

De la misma manera, Valdés emplea su texto autobiográfico para crear su obra. Sor Sebastiana fue digna de veneración. Aparte de tener una existencia virtuosa, tuvo un camino interior hacia la unión con Dios. Su obra presenta numerosos temas que se avecinan al imaginario de la mística (como las visiones y los éxtasis). Mi propósito, en el presente trabajo, es estudiar el lenguaje figurativo del cuerpo hagiográfico. No pretendo discutir la veracidad de la experiencia, pero sí quisiera indagar el carácter de los recursos simbólicos que aparecen en la obra. 


\section{La "opacidad" de la mística peninsular}

Existen numerosas publicaciones que recogen con detalle las fases de la experiencia mística y su explicación ${ }^{1}$. Tradicionalmente la vía mística se divide en tres fases: purgativa, iluminativa y unitiva. La primera requiere tanto una (gran) actividad por parte de la persona mística, ya que como lo anhelado es perfecto, esta también aspira a la perfección. (Underhill 1911, 108). Después de la purgación, viene el periodo iluminativo en el que el místico percibe la belleza de Dios. En la siguiente, sin embargo, tiene que pasar por la "muerte mística" en la que se abandona totalmente a Dios. La última es la unión (Underhill 1911). Por su parte, (Cilvetti 1974, 40) toma la clasificación teresiana y dice que la segunda fase consta de: recogimiento, quietud, sueño de las potencias, unión plena y extática del desposorio. El recogimiento es un "entrarse de las potencias dentro del alma" (20). La quietud implica la unión de voluntad, memoria e imaginación, pero no de entendimiento.

1 Del mundo hispanohablante podemos mencionar, por ejemplo: Cilvetti, Ángel. Introducción al misticismo español. Madrid: Gredos, 1074. Asimismo, Melquiades, Andrés Martín. Los místicos de la Edad de Oro en España y América. Madrid: Biblioteca de autores cristianos, 1996. También Velasco, Juan Martín. El fenómeno místico. Madrid: Trotta, 2003. Es importante también el trabajo de Evelyn Underhill: Underhill, Evelyn. Mysticism: a study in the nature and development of man's spiritual consciousness. London: Methuen and co., ltd, 1911.
La unión plena del desposorio significa una suspensión total de las potencias en Dios y los sentidos externos, pero no es permanente. El recogimiento y la quietud implican que el místico debe abandonar su personalidad y sus facultades mentales para poder llegar a la unión con Cristo. Es un camino ascendente que, sin embargo, desciende hacia el interior del ser. Por eso, según Espinosa (1994), se trata de la vía "oscura".

No obstante, la experiencia de las religiosas novohispanas, como veremos, tiende más hacia la transparencia y la corporalidad. Casi no aparece el tema de la aniquilación "psíquica", pero sí abunda el tema de la mortificación. Los místicos peninsulares y las monjas novohispanas coinciden en la importancia de la purgación activa y en el cultivo de las virtudes frente a las "tinieblas" del pecado.

Por eso, vamos a ver primero cómo se presenta la mortificación del sentido en la obra de sor Sebastiana y cuáles recursos emplea el hagiógrafo para describirla. Luego hablaremos de la cuestión de la virtud. Asimismo, nos detendremos en la cuestión del ascesis natural y del sobrenatural, comparándolo con la obra teresiana.

\section{El ascetismo de sor Sebastiana}

Me gustaría clasificar los tipos de mortificación según los sentidos se ven involucrados en el proceso. En primer 
lugar, está el sentido de la vista. Dice Valdés (1765) al respecto: "Nunca se dio el caso de asomarse a ventana, que saliesse a la calle, pues aun en aquellos dias en que suele haber, y solian passar por su casa devotas Processiones... no pudieron recabar, que se asomasse a ver..." (Valdés 1765, 17). Podemos ver aquí, además, el propósito de elogiar la virtuosidad de Sebastiana mediante el recurso de la hipérbole.

Otro de los sentidos y un gran tema de la hagiografía es el tacto, es decir, lo que atañe al cuerpo como tal. Aparece descrito tanto por la voz de la religiosa como por su hagiógrafo. En ese sentido, podríamos hablar tanto de la experiencia directa como de la interpretación y la reiteración de Valdés. Sebastiana describe sus disciplinas de esta manera:

Nos levantábamos a las cuatro, y se hacía disciplina común, que eran tres todos los días diferentes, de abrojos, otra de ortigas, otra de punta de acero, y varas de membrillo, y de sangre con pomas de vidrio, esta duraba una hora, y más; los cilicios todos los días... Con corona de espinas, y cilicio apretado, hincada para rezar la Corona, con cilicio en las rodillas; cama, y cabecera dura; cruces con la lengua, hasta echar sangre, y mordaza... (Valdés 1765, 45)

Prosigue Sebastiana expresando que "todos los días me ponía un cilicio, que ocupaba desde los [sic] hombros, hasta la cintura para abajo; la disciplina de sangre de hora, por la mucha sangre me desmayaba con mucha congoja, que parecía que me moría..." (Valdés 1765, 46). Sebastiana describe su mortificación con una brutalidad considerable. El cuerpo en este sentido es el obstáculo y a la vez el medio para llegar a Dios. Sin embargo, tiene que ser destruido para poder ser santificado. Observamos además el gusto barroco por lo exuberante y lo morboso. El cuerpo de Sebastiana es el escenario en el cual se desarrolla la pieza teatral de la muerte corporal.

Valdés (1765) repite la manera de mortificación ya descrita por Sebastiana. El hagiógrafo denomina su vestido de abrojos, ortigas y cilicios "gala" que se ponía los días festivos. De esa manera entendemos que para una religiosa el vestido hermoso es el hecho por recursos para la mortificación y no las joyas del mundo. Además Valdés (1765, 333) informa que "en la garganta traía una soga, o gargantilla, que daba vuelta, y ceñía todo el cuello...". El hagiógrafo llama su ejercicio sangriento "su dichosa felicísima crueldad" y también dice todo eso "pone horror solo leerlo" (Valdés 1735, 333). El sacerdote más que añadir información nueva, reitera la descripción de Sebastiana, según las pautas del género, e interpreta su experiencia. Su posición ante los cilicios de la monja es contradictoria, lo cual demuestra la expresión de la dichosa 
crueldad. Por un lado, la mortificación es necesaria para santificar el cuerpo. No obstante, el hagiógrafo admite que tales hechos producen horror en el lector. Aquí podemos observar cierto cambio en la mentalidad barroca. Los hagiógrafos anteriores se asombran ante la mortificación aguda de sus biografiadas para subrayar su heroísmo y santidad. Evidentemente, el propósito de Valdés es también el de elogiar a su personaje. No obstante, vemos, aparte de la admiración, el horror ante la crueldad de la monja.

Otro de los temas es el sentido del gusto. La monja transforma su gusto mediante el ayuno. Sebastiana describe que su mayor trabajo fue el de ser obligada a ingerir alimentos: "Siendo este reparo con más rigor que este Santo Convento, que le hizo muy mal rostro la Madre Maestra a todo, mandándome con enojo, que todos los días había de tomar chocolate, y había de comer carne..." (Valdés 1735, 150).

El gusto está relacionado en la obra con la importancia de la obediencia, ya que Sebastiana se ve obligada por sus superiores a comer dulces en contra de su voluntad (Valdés 1735). La mujer utiliza la comida como una especie de control de su relación con Dios, sin embargo, se enfrenta a la autoridad eclesiástica. Así, Sebastiana obedece la llamada de sus superiores y recibe alimentos.
La mortificación, en el sentido que le ponen los místicos, es el desprendimiento del "apego desordenado de la voluntad y de los sentidos a las criaturas, entendiendo por tales tanto las cosas materiales como las espirituales y divinas" (Cilvetti 1974, 18). Santa Teresa pone atención en el despojo del mundo sensual en el primer grado de oración (en la meditación), cuando expone la parábola del huerto.

De esa manera emplea la parábola del riego y del cultivo del huerto para hablar de los pasos en la oración. El primer estado podría ser relacionado con el esfuerzo de la vía purificadora:

De los que comienzan a tener oración, podemos decir son los que sacan el agua del pozo, que es muy a su trabajo, como tengo dicho, que han de cansarse en recoger los sentidos; que, como están acostumbrados a andar derramados, es harto trabajo. (Santa Teresa 2006c, 72)

Asimismo, Teresa subraya la importancia de apartarse del mundo sensual y reflexionar la vida pasada para poder prepararse al siguiente estado de oración. Por eso dice que "han menester irse acostumbrando a no se les dar nada ver ni oír, y aun ponerlo por obra las horas de oración, sino estar en soledad y, apartados, pensar su vida pasada" (Santa Teresa 2006c, p. 72)

Asimismo, para poder llegar al tal estado aconseja seguir el ejemplo de 
los santos en procurar la vida virtuosa: "También se pueden imitar los santos en procurar la soledad y silencio y otras muchas virtudes, que no nos matarán estos negros cuerpos que tan concertadamente se quieren llevar para desconcertar el alma..." (Santa Teresa 2006c, 79). Explica también: "Paréceme ahora a mí esta manera de caminar un querer concertar cuerpo y alma para no perder acá el descanso y gozar allá de Dios" (p. 79).

En el Camino de perfección (Santa Teresa 2006a, 272) habla también del desprendimiento absoluto de las cosas mundanas:

\begin{abstract}
Ahora vengamos el desasimiento que hemos de tener, porque en esto está el todo, si va con perfección. Aquí digo está el todo, porque abrazándonos con solo el Criador y no se nos dando nada por todo lo criado, Su Majestad infunde de manera las virtudes que, travajando nosotros poco a poco lo que fuere en nosotros, poco tenemos más que pelear...
\end{abstract}

Santa Teresa (2006a, 282) enfatiza el despojo del mundo sensual y hasta del propio sujeto y de su cuerpo: "De cuantas veces os ha burlado este cuerpo, burlas vos de él algún día”. Según la santa, el desprendimiento tiene que ir junto con el camino en la oración, como habíamos visto en la descripción del "agua del pozo". Asimismo, subraya una y otra vez la importancia del abandono totalitario del mundo y de una misma, lo cual incluye el cuerpo.

No desarrolla en su obra la práctica de mortificación como tal, pero podríamos decir que para Santa Teresa es crucial el esfuerzo personal en el abandono del cuerpo y de sí misma para poder emprender el camino de oración y adentrarse en sí misma.

En las Fundaciones (Santa Teresa 2006b, 737) expone: "Han de considerar que esto de mortificación no es de obligación: esto es lo primero que han de mirar. Aunque es muy necesario para ganar el alma libertad y subida perfección ....". De esa manera podemos entender que para la santa la mortificación es un medio que ayuda en el camino espiritual, aunque no sea obligatoria.

Sebastiana habla de su mortificación aguda en el transcurso de sus ejercicios espirituales en los que vive la proximidad íntima de Dios, como veremos. Por eso podríamos suponer que forman parte de lo que es el crecimiento en la relación con su Esposo. Las monjas usan el cuerpo como medio de llegar a Dios, y por eso tratan de disminuirlo, de abandonarlo. El discurso hagiográfico gira en torno de la destrucción corporal. Se trata de la doble postura barroca. Por un lado, está el intento de olvidarse del cuerpo; sin embargo, es esencial en el proceso de santificación: es el escenario donde ocurre su "muerte" y el acercamiento 
a Dios. Santa Teresa emplea lo material y los sentidos como punto de partida. Hay que recoger "los sentidos" y el alma se tiene que quedar "sin ver ni oír”. De allí, continúa el esfuerzo en la meditación que encamina al sujeto para adentrarse en sí mismo.

De igual manera, hay que tener en cuenta los rasgos del género hagiográfico, ya que aunque no aparezca desarrollado el tema de la mortificación en la obra teresiana, sí está presente en su "vida". Ribera (1908, 478) menciona las disciplinas severas que hacía su biografiada como un gesto penitenciario. De esa forma enfatiza sus virtudes heroicas: "Estando en San José de Ávila tomaba también grandes disciplinas de sangre, y de las otras; pero todas le parecían que dolían poco, porque la venían algunas veces unos deseos tan grandes de penitencia, que quisiera despedzar su cuerpo, si fuera conforme a la voluntad de Dios".

Sin embargo, el hagiógrafo ve importancia en la oración mental, un término usado por los místicos y, entre ellos, por santa Teresa. Según ella, es la conciencia de que el alma está presente ante Dios: "Mas si -como es razón-, hablando con tan gran Señor, habéis de estar mirando con quíen habláis y quién sois vos..." (Santa Teresa 2006a, 328).

Valdés (1735, 269) dice que el "acto de la Virtud de Religión es la
Oración. De la mental, que tuvo la Madre Sebastiana, hemos referido algo en varios pasajes de esta Historia, y de alto grado a que llegó, por el esmero con que se destinó a su práctica”.

Vemos que el discurso del hagiógrafo se centra, ante todo, en la mortificación del cuerpo. El texto carece de temas como el recogimiento o la quietud de las potencias. Expresa lo físico y lo tangible de la relación con Cristo. Su escrito se caracteriza por la "transparencia".

Aunque el hagiógrafo mencione cierto progreso en la vida espiritual, no podemos hablar de la experiencia mística propiamente dicha, ya que no está presente el camino místico como tal (incluidas las fases de recogimiento y de quietud), pero sí aparecen temas relacionados con ese campo. Por eso, quisiera dividirlos según los símbolos que tienen que ver con la mística. Trataré los relacionados con el campo de los sentidos: la vista, el oído, el olfato, el gusto y el tacto. A partir de ellos analizaré algunos de los temas que tienen que ver con la experiencia mística.

\section{La "opacidad" y "transparencia" de la imagen mística}

Como la mística se mueve en una realidad sobrenatural, en el intento de expresar lo vivido batalla con la imposibilidad. El lenguaje es inefable, ya que tiene que traducir en palabras el 
secreto de su experiencia. (Underhill 1911, 90) Se trata de la relación paradójica entre la falta de palabras y la necesidad de comunicar la experiencia sobrenatural. Por eso, el signo empleado es el símbolo. El lenguaje simbólico, sugestivo es el de la poesía. De esa manera, el místico-poeta proporciona palabras que logran expresar algo del contenido de la experiencia y a la vez estimulan la intuición del lector. (Underhill 1911). Sin embargo, el símbolo no es perfecto, no logra expresar plenamente su vivencia (Cilvetti 1974).

A pesar de eso, la mística está relacionada con la escritura. Su campo es la palabra. Esta se convierte en traductora de su experiencia y, como dice Certeau (1993, 124), "forma un todo con las incesantes operaciones sobre palabras extranjeras". Según Baldini (1986, 34), "el místico es quien experimenta constantemente con el lenguaje, ya que trata de decir lo indecible".

En cuanto a las figuras estilísticas, la que más expresa lo intangible de la experiencia es el símbolo. Mancho Duque $(1993,138)$ explica que "la característica fundamental del símbolo consiste en evocar, sugerir, implicar, pero nunca señalar con precisión". La autora vuelve a la noción de nebulosidad del recurso simbólico. De allí que uno de sus rasgos fundamentales es su polivalencia significativa. Eso se puede relacionar con el carácter efusivo, espiritual del plano real. Mancho Duque (1993) presta atención al fenómeno de la "condensación significativa" que se produce en el símbolo. Contempla el recurso como una acumulación de significados en diferentes niveles de profundidad, "cada vez más insondables" (139). De esa manera, observa el símbolo como un único organismo, difícil de descomponer en significados parciales. Por otro lado, declara su valor intuitivo e multivalente.

Además, concibe que "el símbolo es un elemento vivo que supone una actividad del interlocutor" (Mancho Duque 1993, 140). Lo que acabo de mencionar se relaciona con su carácter sugeridor como un recurso que suscita, en quien lee, cada vez nuevas interpretaciones y acepciones. Por eso es tan difícil de desentrañar y se pone de lado de la esfera emotiva.

En cuanto a las clasificaciones importantes, destaca la que se basa en la relación del símbolo con la experiencia sensorial. Cuando hablamos del sentido en cuanto a la mística, se trata de un intento de captar realidades espirituales a través de la esfera de lo físico. Habíamos visto que el símbolo como tal refleja la intención del poeta de expresar lo indecible de su vivencia íntima mediante palabras tangibles ( $\sin$ omitir la variedad interpretativa del recurso simbólico). 
La clasificación de Cilvetti (1974, 56) parte de la "comparación" de los cinco sentidos físicos con la experiencia espiritual. La vista está relacionada con la contemplación mística. Mediante el oído el sujeto percibe las palabras de Dios. Las "locuciones" pueden ser corporales, imaginativas e intelectuales. De las primeras dos los místicos desconfían (Cilvetti 1974, 57). De esa manera vemos que el oído se relaciona también con el imaginario cristiano, ya que es el sentido mediante el cual sus fieles reciben mensajes de Dios (por ejemplo en los sermones). El olfato y el gusto expresan el placer de la experiencia mística. La simbología proviene del Cantar de los Cantares. Santa Teresa, por ejemplo, habla de la imagen del brasero donde se echan olorosos perfumes (Cilvetti 1974). El tacto se relaciona con otros sentidos. Muchas veces aparece como uno de los símbolos de la unión mística. Santa Teresa (2006), en las Moradas V, habla del sello que se imprime en la cera. El tacto en la tradición cristiana tiene tanto su aspecto negativo y es cuando simboliza la lujuria, como el positivo: la relación amorosa del alma con Dios. Podríamos decir que tanto la acepción negativa como la positiva comparten un fuerte erotismo.

Otra de las cuestiones a resolver es la relación entre el símbolo y la alegoría que será útil para el análisis de los textos hagiográficos. Guillén (1962,
84) dice que "la poesía y la alegoría se desarrollan en rutas paralelas que, si se mantienen acordes a su definición, no podrán rozarse ni estorbarse". Los dos tropos llegan a intercambiarse a veces, sin embargo, responden a procedimientos poéticos diferentes. Según Ubarri (2001, 61-2), el símbolo crea multiplicidad de interpretaciones, mientras que la alegoría "concreta un corto número de posibilidades significativas para convertir la cadena de símbolos en instrumento de enseñanza".

El rasgo fundamental de la alegoría es su carácter didáctico y carece de opacidad de significado. La poesía es el medio de superación de lo intelectual, lo que sería el ámbito de la alegoría. Nace, como explica Guillén (1962, 84), del "arranque vital". El símbolo está cerca del enigma, pero se limita a las soluciones y está abierto a la posibilidad de ambivalencia. Mientras tanto la alegoría es fácil de leerla. El símbolo no es dado, sino encargado como una tarea sin tener una sola solución. Mathauser (1992) ve su rasgo esencial en su espontaneidad y su carácter alusivo. De allí, como dice Baruzi (2001, 321), el símbolo "traduce una intuición del mundo". Según el autor, los símbolos hacen revivir, en cierto sentido, la experiencia mística, por eso la noche, siendo la ausencia, se convierte en emblema de presencia. Esas imágenes nos hacen "entrar bruscamente en un mundo nuevo" (Baruzi 
2001, 327-8). Para Baruzi (2001, 341) el símbolo verdadero es lo que "hace sentir la hondura de la experiencia"; el "verdadero símbolo se adhiere directamente a la experiencia".

Mientras tanto, la alegoría está entre la explicación didáctica y el arte. Baruzi $(200,339)$ explica que "no emana de la actividad estética en su estado puro". El alegorismo sería, por lo tanto, más bien la traducción de la experiencia, en lo que el simbolismo místico sería la experiencia misma, revivida en el arte. Su entendimiento del pensamiento alegórico se basa, por lo tanto, en la descripción (como dice Baruzi) didáctica de la vivencia mística.

Habíamos visto que la diferencia primordial entre el símbolo y la alegoría está, en el primer caso, en su fuerza de hacer tangible, de alguna manera, lo inefable de la experiencia. Se presta a la multiplicidad de significados e interpretaciones y es ambiguo como es opaca la vivencia mística. Por otro lado, la alegoría no muestra, sino traduce. Es fácil de comprender, ya que es más o menos convencional. Se relaciona con la tradición religiosa anterior y es comprensible comúnmente por el público lector. Sirve como cierto medio de interpretación de las verdades religiosas.

El lenguaje místico es indecible pues tropieza con la imposibilidad de expresar lo que ocurre en la "oscuridad" entre el alma y Dios. Por eso, decía Espinosa que la mística española es la mística de lo opaco y la novohispana es la de la "transparencia". A continuación, vamos a ver si la clasificación entre alegoría y símbolo es útil en el contexto del escrito hagiográfico. Me centraré ante todo en las imágenes que tienen que ver con el campo semántico de luz.

\section{Las visiones}

Para hablar de los símbolos u otros recursos estilísticos en la obra de Valdés (1765), quisiera partir de la clasificación de Cilvetti (1974). En primer lugar, es más general, ya que apunta más bien hacia un tipo de experiencia, que presenta cierta analogía con los sentidos. Por lo tanto, cuando habla del símbolo de la vista, emplea dicho vocablo en su acepción más general, dejando de lado la cuestión literaria sobre la división entre símbolo-símil-metáfora y alegoría.

Cilvetti (1974) distingue entre las visiones corporales, imaginarias e intelectuales. Las últimas son las más perfectas, ya que no pertenecen al ámbito de la imaginación. La percepción corporal es entendida con claridad por el místico, mientras que la intelectual batalla con la inefabilidad: los místicos carecen de la posibilidad de comprenderlas con claridad.

Uno de las figuras y tropos más usados por la santa de Ávila es el símil. 
No se trata, sin embargo, de una imagen sencilla, sino que la carmelita forma una cadena de imágenes relacionadas con cierto campo semántico, por ejemplo, con la luz. Así, trata de explorar exhaustivamente las posibilidades de connotación que posee cada uno de sus recursos. De esa manera, trata de responder a la pregunta de cómo es su experiencia con Dios. Eso, no obstante, no significa que Teresa deje de lado otros, tales como el símbolo o la alegoría. Izquierdo Sorli (1993) afirma que sus textos se ven unificados por el recurso alegórico, que, a la vez, está formado por elementos parciales, por ejemplo, el símil.

Según Fernández Leborans (1978, 57-8), la luz y su campo semántico tiene dos connotaciones primarias. Se trata del semema de "ciencia", "sabiduría" o "conocimiento". Se emplean en el sentido moral y tienen que ver con la "claridad" para obrar de acuerdo con la voluntad de Dios. En este caso se vincula, más bien, con la esfera de lo humano, no en el sentido místico. Fernández Leborans (1978, pp. 57-8) dice: "Si bien se trata de una sabiduría que Dios debe infundir al hombre para que pueda dirigir con rectitud moral su trayectoria vital terrena, no excede los límites impuestos a la naturaleza cognoscitiva humana...”. Por otro lado, Teresa emplea el campo semántico de la luz para referirse a la Divinidad Trascendente (Fernández Leborans 1978). En ambos casos se trata de la connotación afectiva positiva. La luz forma una relación dual con "las tinieblas" que simbolizan los efectos del pecado en el alma y tienen un valor negativo.

\section{Izquierdo Sorli (1993) plantea} que la mística teresiana gira en torno a la luz. El Sol es para ella el símbolo de Dios, y la luz es la comunicación divina con el ser humano. Dentro de ese imaginario existen diferentes símbolos parciales. Se refieren en algunos casos a la gracia divina, a la iluminación, al conocimiento místico y a Cristo. Lo más habitual, sin embargo, es relacionar la vista con el conocimiento profundo de Dios. Es "ver con los ojos del alma”. Aún más importante es la imagen de luz-Cristo, allí tienen su lugar las visiones.

Por lo tanto, la luz, por un lado, tiene que ver con el entendimiento de la voluntad divina, con la vida en gracia divina. Otro significado es el metafísico-místico, según el cual las imágenes luminosas describen el conocimiento sobrenatural de Dios, junto con las visiones que expresan la belleza de Cristo-luz. La vista como sentido espiritual apunta, por lo tanto, hacia la sabiduría profunda de los secretos que Dios revela al alma.

Asimismo, en la iconografía cristiana, la luminosidad está relacionada con el color blanco que tradicionalmente representa la virginidad y la inocencia (Úzquiza Ruiz 2012). 
Este aspecto es importante, como veremos en relación con el alma y la figura de la monja.

En el texto de Valdés (1765), Sebastiana habla de las "vistas amorosas" que le pone Dios. Aquí el campo visual está vinculado al tema del amor, o bien, la monja expresa su relación afectiva con Cristo. El campo semántico del sentido visual tiene que ver con el entendimiento sobrenatural, por un lado; pero este, asimismo, tiene un signo afectivo, se arraiga en la relación amorosa Cristo-Sebastiana. En la "vida" aparecen varias visiones de Cristo y de la Virgen, descritas tanto por Sebastiana como por su hagiógrafo. Valdés narra que en una de las ocasiones se le revela Cristo crucificado. Sebastiana describe su visión como un diálogo amoroso entre ella y su Esposo.

Quexabame (dice) delante de mi Señor crucificado. Y mi Alma le decía todo lo que me acongojaba. Y mirandolo tan lindo, se me encendió el corazón en un amor tan tierno, que me deshacía en lagrymas, sintiendo en mi Alma lo mucho, que por nuestro amor padeció, siendo tan delicado, innocente, y tierno. Le decía yo mil ternuras; porque me mostraba su despedezado, y Purissimo Cuerpo, hablandome por las bocas de sus Santissimas Llagas. (Valdés 1765, 225)

La familiaridad de lo espiritual es de notar en el modo en el que la monja se comunica con Cristo. Él despierta en Sebastiana el sentimiento de lástima y compasión por su padecimiento. Jesús no está descrito como Dios sino un sujeto inocente e indefenso. Mediante la metáfora de la voz de sus llagas, se enfatiza el tema del sufrimiento a través del cual llegó al mundo la redención. Mediante el lenguaje sugestivo de amor entre la monja y su Esposo, Sebastiana logra conmover. Aunque forme parte de la voz de la religiosa, el propósito de Valdés puede ser el de despertar emoción en el público y moverlo hacia la conversión. Otra vez volvemos al tema de la teatralidad y gestualidad del lenguaje barroco que suscita la emocionalidad lectora. La relación íntima de la enclaustrada con el cuerpo de Cristo no es nada casual en el mundo conventual femenino y tiene que ver, por un lado, con el estatus de la monja como esposa, y al mismo tiempo se relaciona con la importancia de "imitatio Christi". En este sentido, la cruz se convierte en la metáfora de la vida conventual (Lavrin 2008, 101). De allí brota la importancia de la mortificación en el texto como la aproximación del sufrimiento de Cristo.

En otra de las ocasiones se le aparece Jesús que llora por la salvación del mundo. Asimismo, esta imagen pretende despertar la compasión en quien lea y el sentimiento de contrición ante sus pecados.

A este tiempo, vi a mi Señor puesto en la Cruz, y con mucho amor; bajó 
un brazo, y abrazó mi Alma, que estaba en el lado del Corazón, con mucha seguridad; y el otro brazo le quedó pendiente de la Cruz. Su amorosísimo Rostro, muy humilde, inclinado a mi lado, y muy lastimado; pero muy lindo, y sus ojos bellísimos, rosados en lágrimas, que se salían como hermosísimas perlas, que causaba ternura, y grande amor; y sin hablar palabra, le dio a entender a el Alma, que de amor lloraba, y el amor le quitaba la vida. (Valdés 1765, 303)

La imagen de Cristo que llora está relacionada con la piedad patética y afectiva de la Contrarreforma. Esto tiene que ver con la "teoría de los afectos”, definida por el teólogo medieval Hugo de san Víctor, según Martínez-Burgos (2010, 35):

Así, la experiencia afectiva, lo que algunos autores llaman "empatía" fue la piedra angular de este arte para la devoción con el que se persigue crear un estado psicológico determinado. En realidad, la imagen de devoción se distingue porque estimula a la conciencia individual del espectador para que realice una verdadera inmersión contemplativa en el contenido...

En este sentido podríamos decir que el discurso de Sebastiana funciona como la imagen devocional barroca y suscita una respuesta emocional en el lector o lectora, además de estimular la contemplación sobre el sufrimiento de Cristo. Por eso, podemos decir que la visión de Sebastiana refleja la piedad barroca.

Otra de las visiones es la de María. Lavrin (2010) expone que la Virgen fue vista desde la Edad Media como la protectora universal de la humanidad a través de la relación con su Hijo. Podemos decir que María es, por un lado, la mediadora, pero además como la Madre de Cristo extiende su maternidad a sus esposas virginales. De allí, podemos hablar del tema del hogar que aparece en la hagiografía femenina. La Virgen, Cristo y los santos forman parte de la familia espiritual y sobrenatural de la monja. Sebastiana expresa:

... miraba a mi Madre de mi Alma María Santissima, y todo mi consuelo. Me quejaba, abrazada en sus divinos brazos, y alli abrazada mi Alma, se me deshacía el corazón, solo de ver, con mucho amor, y ternura, que me quedé tan encogida, como avergonzada, y agradecida... (Valdés 1765, 238)

Sebastiana, en su discurso, pasa de lo corporal y emocional (el abrazo, las lágrimas) a la esfera espiritual ("abrazada mi Alma..."). Parece que la visión es llevada a términos de lo corporal más que intelectual o imaginario, aunque finalmente habla de su alma. Sin embargo, se queda en el ámbito de las emociones cuando dice que estaba "avergonzada y agradecida". Parece que se mezclan en ella diferentes estados de ánimo que son producidos 
por el encuentro sobrenatural. Como habíamos visto, mucho se ha discutido el problema de la mística en los textos novohispanos, la comunicación de la visionaria y los seres sobrenaturales tiene lugar en el ambiente de los sentidos. Asimismo, parece ser el caso de Sebastiana, lo cual se debe ante todo al contacto "físico" entre la enclaustrada y la Virgen mediante el abrazo. Por otro lado, como sabemos, los símbolos místicos se centran en lo sensual. Por eso, aquí la vista como un símbolo místico podría estar relacionada con el sentido del tacto espiritual.

Por lo general, podemos decir que las visiones de Sebastiana se mueven entre la ternura y emoción, si se trata de Cristo y la Virgen. Sin embargo, si su propósito es enseñar el horror del pecado, aparecen imágenes terroríficas y brutales. La experiencia de Sebastiana se mueve entre la crueldad de su mortificación y la ternura de la relación con los seres sobrenaturales. Allí podemos observar la paradoja del lenguaje barroco. La teatralidad de la imagen está enfatizada por las lágrimas de Cristo y por lo físico de la relación esposa-Esposo.

Como habíamos visto, existen varios tipos de visiones. Santa Teresa describe las intelectuales como las más perfectas en las que el demonio puede engañar menos.
Así es también en otra manera que Dios enseña el alma y la habla sin hablar, de la manera que queda dicha. En un lenguaje tan del cielo, que acá se puede dar a malentender, aunque más queramos decir, si el alma entienda, en lo interior del alma, y allí lo representa sin imagen ni forma de palabras, sino a manera de esta visión que queda dicha. (Santa Teresa 2006c, 144)

En este sentido, nos damos cuenta de que las visiones de Sebastiana no son intelectuales, más bien tienen lugar en lo corporal y lo imaginario. A la santa se le representa Cristo de diferentes maneras, como la misma dice:

Casi siempre se me representaba el Señor así resucitado, y en la Hostia lo mismo, si no eran algunas veces para esforzarme si estaba en tribulación, que me mostraba las llagas, algunas veces en la cruz y en el Huerto y con la corona de espinas, pocas; y llevando la cruz también algunas veces... (Santa Teresa 2006c, 155)

En una de ellas se le aparece Cristo crucificado:

Aparecióme como otras veces y comenzóme a mostrar la llaga de la mano izquierda, y con la otra sacaba un clavo grande que en ella tenía metido. Parecíame que a vuelta del clavo sacaba la carne. Véase bien el gran dolor, que me lastimaba mucho... (Santa Teresa 2006c, 215) 
La pasión de Cristo y su sangre aparecen ya en las visiones de santa Catalina de Sena. Teresa enfatiza el dolor de Jesús mediante la imagen de su carne sacada por los clavos. Al contrario del texto de Sebastiana, su revelación no produce una compasión tierna, sino sentimiento de terror.

En una de las ocasiones se le representa la Virgen y San José. Teresa la describe como un personaje de mucha belleza: "Era grandísima la hermosura que vi en nuestra Señora, aunque por figuras no determiné ninguna particular, sino toda junta la hechura del rostro, vestida de blanco con grandísimo resplandor..." (Santa Teresa 2006, 183). Aquí está la representación de los seres celestiales como hermosos y resplandecientes, lo cual tiene que ver con la oposición de cielo como el lugar de luz y belleza, y el infierno como un ámbito desagradable y oscuro. Además, está la oposición entre el vestido blanco de la Virgen y el color negro del demonio, como ya habíamos visto. Aquí la blancura tiene que ver con la bondad de María. Así como en el discurso de Sebastiana, la Virgen se presenta aquí con cierta familiaridad. Santa Teresa (2006, 182) manifiesta, por ejemplo: "... luego me pareció asirme de las manos nuestra Señora...".

Las visiones de Sebastiana (mucho más que en el caso de Teresa) tienden hacia la familiaridad del discurso y pretenden producir una reacción afectiva en el público interlocutor. Parece que tiene lugar ante todo en el escenario del cuerpo. Así la religiosa abraza y besa a su Esposo, lo trata como si fuera un ser físico más que espiritual. Santa Teresa es mucho más esquiva al hablar de sus visiones. El discurso del hagiógrafo y la religiosa se mueven hacia la "transparencia". No hay falta de palabras, más bien aparece la exageración hagiográfica.

En cuanto a la luz, hablaremos primero de su significado de conocimiento sobrenatural de Dios (Fernández Leborans 1978), en concreto veremos una imagen de Cristo-luz y sus efectos en el alma:

No es resplandor que deslumbre, sino una blancura suave y el resplandor infuso, que da deleite grandísimo a la vista y no la cansa, ni la claridad que se ve para ver hermosura tan divina. Es una luz tan diferente de la de acá, que parece una cosa tan deslustrada la claridad del sol que vemos, en comparación con aquella claridad y luz que se representa a la vista, que no se querrían abrir los ojos después. (Santa Teresa 2006c, 150)

Aquí presenta una oposición entre la luz "de acá" y la otra "la diferente". Describe la imagen de Dios mediante el sustantivo "blancura", "resplandor". Es una luz que no cansa y que "da deleite". Tanto como en las 
"vistas amorosas" de Sebastiana, en el imaginario teresiano la luz se relaciona con los efectos positivos, con el gusto y el amor. Asimismo, la luminosidad divina está simbolizada por el color blanco. Es una luz "infusa”, recibida y sobrenatural. Este símil proviene, al parecer, de la imagen bíblica del contraste en el "reino de la luz" y "reino de las tinieblas" (Andueza 1998, 182). Este contraste es palpable en una visión de Teresa cuando le protege "una gran claridad" de los ataques demoniacos (Santa Teresa 2006c, 168).

En la "vida" de Sebastiana aparece la imagen de la claridad relacionada con su alma. En una de las visiones de Cristo muestra su interior. Valdés $(1765,302)$ plantea que es una "cosa muy blanca y de una claridad inexplicable". Con respecto a la explicación anterior, podemos entender la imagen del alma clara de Sebastiana como una referencia al resplandor de Dios, lo cual implica que la gracia sobrenatural está presente en su interior. Además, como habíamos visto, la blancura simboliza la inocencia y la virginidad. Sabemos que la castidad es uno de los cuatro votos perpetuos.

Según Cilvetti (1974, 20), la característica principal de la vía iluminativa es la "luz infusa". Teresa habla de "la luz que no tiene noche" (2006c, 150). Sebastiana expresa que estaba "en tan clara luz de Dios" (Valdés
$1765,40)$. Esta la penetra y le produce arrobamientos. Asimismo, cuando habla de su experiencia habla de la "luz interior" (Valdés 1765, 40).

Otro de los grandes temas de la literatura mística es el símbolo del fuego. Este se relaciona en la simbología cristiana con la fuerza del Espíritu Santo que inflama el alma en el amor de Dios. El fuego es el símbolo de la esencia divina. Es el elemento transformante que tiene la fuerza regenerativa. Es elusivo, pero a la vez capaz de hacerse sentir. Además, en el imaginario cristiano tiene que ver tanto con aspectos positivos como con negativos. Se habla del fuego purificador, pero también de las llamas del infierno. En la simbología mística el fuego está relacionado con la unión y con la imagen del amor pasional (Howe 1998).

En la obra teresiana, el campo semántico del fuego tiene asimismo varias connotaciones. Se trata de la actividad de Dios en el alma: "Es pues, esta oración una centella que comienza el Señor a encender en el alma del verdadero amor suyo, y quiere que el alma vaya entendiendo qué cosa es este amor con regalo" (Santa Teresa 2006c, 88). En el campo del fuego está presente la connotación del amor divino mucho más que en la luz. Esta última refleja también lo sobrenatural, pero en su imagen de inocencia, castidad y entendimiento. En cuanto al fuego, se 
subraya mucho más el amor relacionado con el significado de calor y fuerza. Dios hace que el alma "se queme en el fuego de aquella vela divina" (Santa Teresa 2006c, 98). El verbo "quemarse" remite a la fuerza y "voracidad" de la actividad divina. Santa Teresa (2006c, 529) utiliza, al mismo tiempo, la figura del "brasero":

Estaba pensando ahora si sería que en este fuego del brasero encendido, que es mi Dios, saltaba alguna centella y daba en el alma, de manera que se dejaba sentir aquel encendido fuego, y como no era aún bastante para quemarla y él es tan deleitoso, queda con aquella pena, y al tocar hace aquella operación. Y paréceme es la mejor comparación que he acertado a decir. Porque este dolor sabroso -y no es dolor- no está en un ser; aunque a veces dura gran rato, otras de presto se acaban...

Dios es el agente de la transformación del alma, mientras que esta es más bien pasiva, lo cual vemos en los verbos reflexivos como "se dejaba sentir”. Además, el fuego se relaciona con la pasión amorosa y el dolor. Por eso, Teresa habla de lo "deleitoso" y "el dolor sabroso". El fuego es el símbolo de la unión y de la consumación de amor entre el alma y Cristo.

La experiencia de Sor Sebastiana en relación con el símbolo de fuego es mucho más abstracta. Valdés relata que "la Madre Sebastiana se hallaba tan entregada a el Amor divino, abrasándose viva en sus llamas; de este fuego brotaban centellas de la mayor gloria de su Amado, y ... anhelaba, a que todos se quemasen vivos en tan divina hoguera" (Valdés 1765, 228). Parece que el hagiógrafo utiliza ciertos símbolos como "llamas", "centellas", "hoguera". Pero no expresan la profundidad de su experiencia. Asimismo, es el símbolo del amor divino, pero no tanto en la relación con lo erótico-pasional y la unión mística. Más bien refleja el amor de Sor Sebastiana y su deseo de que todos vivan de la misma manera. Los dos discursos, sin embargo, comparten la pasividad del alma que se deja abrasar por las "llamas". La monja es como la leña que se deja quemar por Dios.

El discurso hagiográfico, además, sale de los límites de lo simbólico. Parece que lo lleva a términos del mundo físico: "... y era tal el incendio de caridad, que abrigaba en su pecho, que no pudiendo contenerse en la limitada clausura de su interior, se vertía en llamas a su rostro, llegando a ser tan sensiblemente incendio, que hubo vez que le abrasó el Velo" (Valdés 1765, 34). Aquí, además, el fuego tiene que ver con el Espíritu Santo que habita en el alma. La primera parte de la oración es alegórica, cuando el hagiógrafo habla del "incendio de caridad", se trata de la hipérbole, pero sigue siendo parte de la experiencia interior, aunque algo abstracta. Sin embargo, la segunda parte presenta un salto de lo interior a 
lo corporal. Valdés (1765) cuenta que incluso una vez parecía que Sebastiana iba a incendiar el monasterio, por eso las monjas decidieron apagarlo.

\section{Conclusiones}

Habíamos visto que el campo semántico de luz se relaciona con la actividad divina y el entendimiento que da el Espíritu Santo. En la obra teresiana y en la de Sebastiana tiene más o menos la misma forma. Lo que difiere en los dos discursos son las visiones y la imagen del fuego. En santa Teresa, las visiones son descritas con cierta austeridad, mientras que en la obra hagiográfica proliferan descripciones detalladas de los encuentros amorosos con Cristo. Parece que el cielo es un lugar familiar, lo cual forma parte de la devoción barroca. El texto de Sebastiana está marcado por la transparencia de la imagen y por la abundancia de la palabra. Por un lado, tiende hacia la familiaridad del contacto con lo sobrenatural en las visiones. Por otra parte, presenta una cierta abstracción en cuanto al campo semántico del fuego. Parece que el hagiógrafo se sirve de ciertas imágenes simbólicas (místicas) y las usa en un modo convencional. Además, pasa de una descripción de lo personal e intangible a lo físico del cuerpo. El fuego espiritual de Cristo se convierte en un incendio real que quema el velo de la monja. Parece que lo importante es el cuerpo, aunque lo que pretenden purificar y salvar es el alma.

\section{Bibliografía}

Andueza, María. 1998. Agua y luz en santa Teresa. México: UNAM.

Baldini, Massimo. 1986. Il linguaggio dei mistici. Brescia: Queriniana.

Baruzi, Jean. 2001. San Juan de la Cruz y el problema de la experiencia mística. Valladolid: Junta de Castilla y León.

Certeau, Michel de. 1993. La fábula mística: Siglos XVI-XVII. México:Universidad Iberoamericana.

Cilvetti, Ángel. 1974. Introducción a la mística española. Madrid: Gredos.

Espinosa Fernández de Córdoba, Carlos. 1994. El cuerpo místico en el barroco andino. En Bolívar Echeverría (Comp.), Modernidad, mestizaje cultural, ethos barroco. México: UNAM/El Equilibrista.

Fernández Leborans, María Jesús. 1978. Luz y oscuridad en la mística española. Madrid: Cupsa Editorial.

Guillén, Jorge. 1968. Lenguaje y Poesía. Madrid: Revista de Occidente.

Howe, Teresa. 1998. Mystical imagery. New York: Peter Lang.

Ibsen, Kristine. 1998. The hiding places of my power: Sebastiana Josefa de la Santísima Trinidad and the Hagiographic 
representation of the body in colonial Spanish America. Colonial Latin American Review, 7(2), 251-70.

Izquierdo Sorli, Monteserrat. 1993. Teresa de Jesús, una aventura interior. Ávila: Institución Gran Duque de Alba.

Lavrin, Asunción. 2008. Brides of Christ: Conventual life in colonial Mexico. California: Stanford University Press.

Mancho Duque, María Jesús. 1993. Palabras y símbolos en san Juan de la Cruz. Madrid: Fundación Universitaria Española/Universidad Pontificia de Salamanca.

Martínez-Burgos García, Palma. 2010. Las pautas doctrinales de la imagen devocional en el arte barroco. En Pedro Ibáñez Martínez, Carlos Julián Martínez Soria (Eds.), La imagen devocional barroca. Castilla La Mancha: Universidad Castilla La Mancha.

Mathauser, Zdeněk. 1998. Metodologické meditace. Brno: Blok.

Ribera, 1908. Vida de santa Teresa de Jesús. Barcelona: Gustavo Gili.

Santa Teresa de Jesús. 2006a Camino de perfección. Madrid: Biblioteca de autores cristianos.

Santa Teresa de Jesús. 2006b. Fundaciones. Madrid: Biblioteca de autores cristianos.
Santa Teresa de Jesús. 2006c. Libro de la vida. Madrid: Biblioteca de autores cristianos.

Ubarri, Miguel Norbert. 2001. Categorías de espacio y tiempo en San Juan de la Cruz. Madrid: Espiritualidad.

Underhill, Evelyn. 1911. Mysticism: a study in the nature and development of man's spiritual consciousness. London: Methuen and co.

Úzquiza Ruiz, Teodoro. 2012. Símbolos en el arte cristiano. Burgos: Sembrar.

Valdés, José Eugenio. 1765. Vida admirable y penitente de la V.M. Sor Sebastiana Josepha de la SS. Trinidad, Religiosa de Coro, y Velo negro en el Religiosissimo Convento de Señoras Religiosas Clarisas de San Juan de la Penitencia de esta Ciudad de Mexico. México: Imprenta de la Biblioteca Mexicana. 
